\title{
THE USE OF NF AND RO MEMBRANE SYSTEM FOR RECLAMATION AND RECYCLING OF WASTEWATERS GENERATED FROM A HARD COAL MINING
}

\author{
Y. Yildirim ${ }^{1, *}$, A. K. Topaloğlu², M. Ince ${ }^{3}$ and M. N. Kajama ${ }^{4}$ \\ 1, 2, DEPARTMENT OF ENVIRONMENTAL ENGINEERING, ZONGULDAK BULENT ECEVIT UNIVERSITY, TURKEY \\ 3, DEPARTMENT OF ENVIRONMENTAL ENGINEERING, GEBZE TECHNICAL UNIVERSITY, TURKEY \\ 4, 144 Shariff Ibrahim Saleh Street, GWANGe WARD, MAIDUGURI, BoRno StATE. NIGERIA \\ E-mail addresses: ${ }^{1}$ yilmaz.yildirim@beun.edu.tr, ${ }^{2}$ alikemal.topaloglu@beun.edu.tr, \\ 3 mahirince@gtu.edu.tr, 4 mohd_nasiru@yahoo.com
}

\begin{abstract}
In this study, the possibility of treatment of wastewater generated from underground hard coal mining excavation was experimentally investigated using Nano filtration (NF) and Reverse Osmosis (RO) membrane systems. Two-stage sequential treatment method was applied to perform the study. In the first stage, the raw wastewater was treated using NF membrane filtration system without any pre-processes. In the second stage, the effluents of NF membrane system were fed into RO membrane system for the treatment. To determine the treatment performance of the NF and $R O$ membrane system, the operating pressures were fixed at 10, 20 and $30 \mathrm{bar}\left(\mathrm{KN} / \mathrm{m}^{2}\right)$ for both systems during the experimental study. Turbidity, sodium, calcium, magnesium, manganese, iron, copper, aluminium, ammonium, sulphate and electrical conductivity were analysed in raw wastewater and permeate flow of $\mathrm{NF}$ and $\mathrm{RO}$ membrane systems to determine the treatment performances. Treatment performance of $R O$ membrane system was observed to have highest yield of $80 \%$ for all parameters examined at 20 bar operating pressure.
\end{abstract}

Keywords: Polymeric membrane, wastewater treatment, coal excavation, water recycle and reuse.

\section{INTRODUCTION}

Water resources of several regions and countries are expected to have shortage in the near future due to continuing population growth and unequal distributions of water and population increases [1]. To overcome this shortage, wastewater from different sources can be used as an alternative water resource to reduce the demands for fresh water [2]. In the industry, reclamation (recovery and treatment of wastewater for reuse) and recycling (recovery and reuse, whether or not subject to treatment) are important. Although, there are many alternative methods to handle the reclamation or recycling of wastewater. Membrane processes provide important and reliable solution for wastewater treatment for reuse, recovery and recycle of the waste streams instead of discharge [3].
The membrane process has been used in applications such as wastewater treatment, industrial water production, water softening, and separation of compounds that having different molecular weights. The recent studies regarding the membrane technologies indicate that the membrane process applications is useful for providing the high-quality drinking water and increasing the re-use of wastewater in the industrial water production. Pressure driven membrane processes such as nanofiltration (NF) and reverse osmosis (RO) have become an important alternative water treatment technology to increase water supplies from alternative sources [1]. One of the most exciting membrane technologies is NF which has potential of selective separations at moderate pressures. NF membrane separation falls between reverse osmosis

* Corresponding author, tel: +90 - 372 - 291 - 2626 
and ultrafiltration with a MW cut-off ranging from 200-1000 Daltons. NF membranes have higher permeability for monovalent salts such as $(\mathrm{NaCl}, \mathrm{KCl})$ and organic compounds with low molecular weight, i.e., lower than 300D [4-6]. On the other hand, RO membrane allows to remove above $99 \%$ of dissolved salts as well as of organic molecules in low molecular mass [7]. RO membrane systems have been used extensively in seawater desalination and the process have nearly $20 \%$ of all desalinated water produced in the world [8]. In many applications, NF and RO membranes have been used together to treat industrial wastewater from different sources [9]. These include; wastewater from steel industry [10], wastewater from food processing industries [11], wastewater from dairy industry $[12,13]$ and wastewater from textile industry [14-18]. NF and RO membranes have also been used to remove, recover and reuse of valuable or contaminant materials from the industrial discharge water such as removal of fluoride and phosphate from fertilizer factory [19], removal of macromolecules and ions from textile and treated effluent [16]. In addition to, instead of using $\mathrm{NF}$ and RO membrane systems alone, using combination of these membrane systems is more effective [17].

Consequently, mining industry, i.e., mineral processing or the excavation consumes huge amounts of water and produces wastewater that should be controlled and treated before discharged. Wastewaters from various mining industries have been studied for treatment and reuse the water for different purposes. Coal mining wastewaters which include generally saline, with very high concentration of suspended solids and variable concentrations of iron, aluminium and dissolved organic matter [2021]. Treatment of wastewater from coal mining prevents the effect of pollution damaging to receiving waters and wastewater treated could be reused for other purposes. In mining, water management can be used as a sustainable approach by optimal water [22]. The wastewater produced from mining facilities is generally treated by means of coagulation/flocculation process. Some of the wastewater treatment from mining processes are to develop a novel polymeric flocculant for the treatment of coal mine wastewater [23], to use lagoons and wetlands for passive coal mine water treatment systems [24], to develop a methodology for assessing the iron removal efficiency in settling lagoons and reed beds [25], to investigate the performance of a polytitanium based coagulant wastewater produced in coal mining activities [21], to remove inorganic pollutants, sulphides and heavy metal from the mine wastewater [26], to treat brackish water [27], to separate metal and sulphuric acid from gold mining effluent[ 7] and to treat coal mine water using a vacuum membrane distillation [22]. There are many researches and studies are carried out to handle wastewater from various mining industry, these are some few available studies used to know about wastewater management from underground coal mining excavation.

Coal mining is a significant supply in very much places of the world as well as in Turkey. A lot of wastewater is pumped to be discharged out to the ground surface from the working areas of coal mines [22]. Treatment of the wastewater from a coalmine prevents serious damage to receiving environment and can be reused for different purposes such as irrigation and bath water after the membrane treatment for mining worker [28]. Water recovery in mining advocates a sustainable and cheaper approach of using treated water instead of fresh water sources. However, a number of traditional technologies have begun to address the treatment of coal mine wastewater for reclamation and recycling. A small number of studies have carried out on low energy and chemical free treatment techniques, such as the membrane systems. The goal of this study is to apply a NF and RO combined membrane system to wastewater reclamation from coal mining excavation which can produce a high-quality clean water using low energy consumption and reduced usage of chemicals as against to traditional wastewater treatment systems. For this purpose, wastewater from hard coal mining excavation in Kozlu province was treated using NF and RO flat sheet membrane system at 10, 20 and 30 bar across the membrane pressure. Before and after the experiments, turbidity, conductivity, ammonium, $\mathrm{Al}, \mathrm{SO}_{4}^{-2}, \mathrm{Mg}, \mathrm{Ca}, \mathrm{Mn}, \mathrm{Fe}, \mathrm{Na}$ and $\mathrm{Cu}$ as parameters were analysed to calculate the efficiency of the membrane systems.

\section{MATERIALS AND METHODS}

\subsection{The mining area and wastewater discharge}

In this study, the wastewater to be treated was obtained from hard coal mining in Kozlu province, Zonguldak, Turkey. City of Zonguldak is located the black sea coast northwest of Turkey which has the biggest underground hard coal mining area in Turkey. Hard coal mining production in the province has 
significant environmental concerns, especially the discharge of mining wastewater directly into the surrounding receiving bodies, i.e., Kozlu stream. An average of $11000 \mathrm{~m}^{3}$ per day of the wastewaters is pumped from 500 meters of underground and discharge into the stream in Kozlu province [28].

\subsection{Membranes}

The separation performances of the two commercially available membranes were experimentally figured out to treat wastewater from the hard coal mining site in this study. Two of them namely NF-270 (NF Membrane - Dow-FilmTech ${ }^{\mathrm{TM}}$ ) and BW-30 (RO Membrane - Dow Film Tech ${ }^{\mathrm{TM}}$ ) are thin-film polyamide membranes with a negatively charged surface. Some characteristics of the membranes areas given in Table 1 .

\subsection{Composition of Hard Coal Mining Water}

Composite sampling of the wastewater obtained from the hard coal mining area of Kozlu province was carried out for homogeneous wastewater samples performing one sample per hour for an 8-hour period. The wastewater was used for treatment in the lab scale membrane filtration systems (Figure 1). The colour of the wastewater sample was black due to suspended materials in coal mine and contains different ions including some heavy metals, earth crustal metals, sodium and sulphate. The chemical composition of the wastewater is shown in Table 2. The wastewater showed high content of turbidity, sodium and ammonium. However, the same samples showed low concentration of other water quality parameters listed in Table 2.

\subsection{Experimental set-up}

NF and RO tests were performed using a lab scale cross-flow flat sheet membrane system. The flow sheet of the membrane filtration system is shown in Figure 1. The system consists of waste water feed tank, flow meter, high pressure pump, pressure gauges, membrane housing, electronic balance and a computer. The lab scale experimental set up was used for the membrane treatment studies using two different PTFC made NF and RO polymeric membranes.

These membranes consist of flat sheet in shape with an effective membrane area of $140 \mathrm{~cm}^{2}$. The membranes were placed between the two stainless steel cell compartments which were tightly clamped together using a hydraulic device.

Table 1: Characterization of the membranes $N F$ and $R O$ membranes

\begin{tabular}{ccccccc}
\hline Designation & Polymer & Rejection $(\mathrm{NaCl})$ & MWCO $(\mathrm{Da})$ & T-max $\left({ }^{\circ} \mathrm{C}\right)$ & P-max $(\mathrm{bar})$ & $\mathrm{pH}$ \\
\hline NF-270 & PTFC & $40-60 \%$ & $200-300$ & 45 & 41 & $3-10$ \\
BW-30 & PTFC & $99 \%$ & - & 45 & 41 & $3-10$ \\
\hline
\end{tabular}

Table 2: Comparison coal mining wastewater characteristics with both TS266 and WHO water quality criteria

\begin{tabular}{|c|c|c|c|c|}
\hline Parameter & Unit & wastewater & TS266 & WHO \\
\hline Al & $\mathrm{mg} / \mathrm{L}$ & 0.0096 & 0.2 & 0.1 \\
\hline $\mathrm{NH}_{4}{ }^{+}$ & $\mathrm{mg} / \mathrm{L}$ & 2,89 & 0.5 & 1.5 \\
\hline $\mathrm{Na}$ & $\mathrm{mg} / \mathrm{L}$ & 389 & 200 & 200 \\
\hline $\mathrm{SO}_{4}^{-2}$ & $\mathrm{mg} / \mathrm{L}$ & 12,6 & 250 & 500 \\
\hline Mg & $\mathrm{mg} / \mathrm{L}$ & 33.62 & n.p. ${ }^{b}$ & n.p. ${ }^{b}$ \\
\hline $\mathrm{Ca}$ & $\mathrm{mg} / \mathrm{L}$ & 31.10 & n.p. ${ }^{b}$ & 300 \\
\hline $\mathrm{Mn}$ & $\mathrm{mg} / \mathrm{L}$ & 0.003 & 0.05 & 0.1 \\
\hline $\mathrm{Fe}$ & $\mathrm{g} / \mathrm{L}$ & 0.1 & 0.2 & 0.3 \\
\hline $\mathrm{Cu}$ & $\mathrm{g} / \mathrm{L}$ & 0.07 & 2 & 2 \\
\hline Turbidity & NTU & 91 & 1 & 5 \\
\hline & - & 8.9 & $6.5-9.5$ & $6.5-8.0$ \\
\hline Conductivity & $\mu \mathrm{s} / \mathrm{cm}$ & 1656 & 2500 & 2500 \\
\hline
\end{tabular}

${ }^{\mathrm{b}}$ Not proposed as health-based guideline.

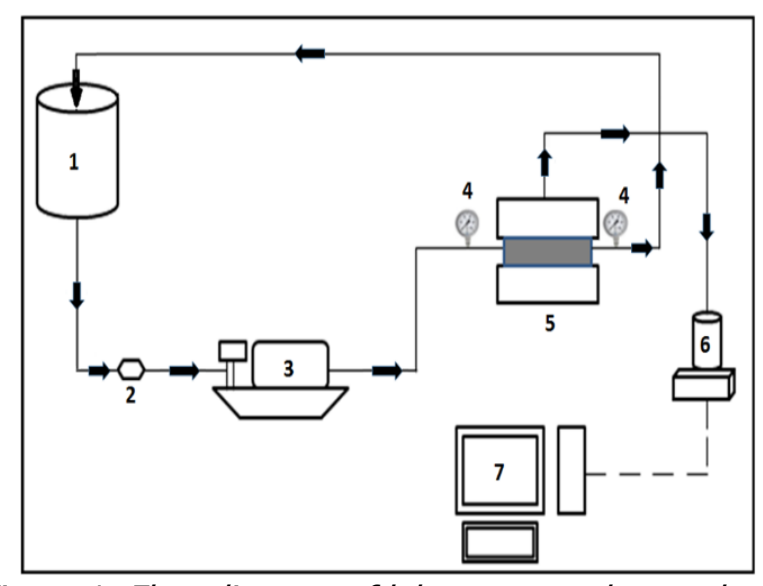

Figure 1: Flow diagram of laboratory scale membrane systems (1. Waste water tank 2. Flow meter 3. High pressure pump 4. Pressure gauge 5. Membrane housing 6. Electronic balance 7. Computer). 
The silicone rubbers were used for sealant agents in the membrane housing. The membranes were immersed for at least for $60 \mathrm{~min}$ in deionized water (15-25 $\mu \mathrm{S} / \mathrm{cm})$ before the wastewater treatment experiment.

\subsection{Sampling and testing methods}

The sampling were performed on samples obtained from feed and permeate sides. Feed sample was taken from the feed tank and permeate sample was taken from the permeate tank. Pressure, feed flow rate, permeate flow rate (permeate flux) were recorded using a computer system. Conductivity, sample temperature, $\mathrm{pH}$ and turbidity were determined with a termo scientific orion 9157BNMD, a termo scientific orion $013005 \mathrm{MD}$ and MicroTPI turbid meter, respectively. Samples were analysed for metals and cations by using Perkin-Elmer (USA) Nexion 300D ICPMS. Ammonium, sulphate and sodium were analysed by using Thermo Scientific Dionex ICS- 1100 .

\subsection{Raw Wastewater Examination}

The composite samples of wastewater were used in the cross-flow membrane filtration systems. The wastewater samples had black colour due to the coal's nature, and the wastewater contains different ions including some heavy metals, earth crustal metals, sodium and sulphate. The ion composition of the water is shown in Table 2. Turbidity, sodium and ammonium were found as high in the samples. However, the samples had low concentration values for the other water parameters listed Table 2. As seen in Table 2, all parameters except turbidity, ammonium and sodium are below the limits of drinking water standards of both [28] and [29].

\subsection{Permeability and Rejection of the Membranes}

Water flux measurements were carried out with high purity Mill-Q water $(15-55 \mu \mathrm{s} / \mathrm{cm})$ from filtration test at different transmembrane pressures $(10,20$ and 30 bar) at an ambient temperature. The pure water fluxes for both membranes (NF270 and BW30) were determined using the membrane effective area of 140 $\mathrm{cm}^{2}$. The pressures were varied between highest pressure of 30 bar to the lowest pressure of 10 bar. Transmembrane pressure and volumetric flow rate were adjusted using the concentrate outlet valve and different speed key of the pump. Pure water flux at certain pressure can be defined and calculated using equation (1);

$$
J_{v}=\frac{Q}{A}
$$

Where $J_{v}$ is permeate flux $\left(L / m^{2} h\right), A$ is effective membrane area $\left(\mathrm{m}^{2}\right)$ and $\mathrm{Q}$ is volume flow rate $(\mathrm{L} / \mathrm{h})$. In this study, the pure water flux was determined by weighing the obtained permeate during a predetermined time using an electronic balance (A\&D EJ-6100 digital scale) connected to a computer. Afterwards, weights of the obtained permeate were converted to $\mathrm{L} / \mathrm{m}^{2} \mathrm{~h}$ and the rejections were calculated using equation (2);

$$
R(\%)=\left(1-\frac{C_{i, p}}{C_{i, f}}\right) \times 100
$$

The rejections were also calculated by using the conductivity ratios using equation (3);

$$
R(\%)=\left(1-\frac{K_{p}}{K_{f}}\right) \times 100
$$

Where $\mathrm{C}_{\mathrm{i}, \mathrm{p}}$ and $\mathrm{C}_{\mathrm{i}, \mathrm{f}}$ are the permeate and the feed concentration of the solute $i$ and $\mathrm{K}_{\mathrm{p}}$ and $\mathrm{K}_{\mathrm{f}}$ the permeate an feed conductivity respectively.

\section{RESULTS AND DISCUSSION}

\subsection{Flux and Rejection vs Pressure}

In the wastewater treatment, experimental applications of membrane filtration processes were obtained for ground water treatment and these applications were carried out under different transmembrane pressures for both NF270 and RO membrane filtrations. Fig. 2 shows the pure water flux and wastewater flux of NF270 and RO membranes. Pure water flux of both NF270 and RO membranes were calculated as 6.08 and $4.16 \mathrm{~L} /\left(\mathrm{bar} . \mathrm{m}^{2} . \mathrm{h}\right)$ respectively. Additionally, while wastewater permeate flux of NF membrane under 10 and 30 bar were 61 and $146 \mathrm{~L} /\left(\mathrm{m}^{2} \times \mathrm{h}\right)$ respectively, wastewater permeate flux of RO membrane under 10 and 30 bar were 43 and $65 \mathrm{~L} /\left(\mathrm{m}^{2} \times \mathrm{h}\right)$ respectively. Consequently, as transmembrane pressure increases, permeate fluxes increased. Pure water and permeate fluxes of the NF and RO membranes resulted in different permeability values, that is, the pure water fluxes recorded higher permeability's.

\subsection{Removal Performances of NF and RO membranes}

Table 3 has been shown only 20 bar permeates for both NF and RO. The analysis of these permeates at 
20 bar pressures for both NF and RO is presented in Table 4. Removal of wastewater at 20 bar for both NF and RO is higher than that of 10 and 30 bar for NF and RO. According to TS 266 and WHO, wastewater treated using NF membrane at 20 bar feed pressure is in the range of drinking water quality standards except ammonium, turbidity and sodium. Whereas, wastewater treated using RO membrane at 20 bar feed pressure is in the range of drinking water quality standards.

\subsection{Selectivity Performances of NF and RO Membranes}

Fig. 3 shows the rejections for different ions including turbidity using NF and RO polymeric membranes at a pressure difference of 20 bar. Results from the nanofiltration and reverse osmosis treatment indicated that the rejections higher than $50 \%$ for polyvalent ions (like dissolved metals) as well as sulphate, ammonium and turbidity except $\mathrm{Na}^{+}$. From the results, sodium rejection of the NF membrane were found to be low for the rejection of monovalent ions due to typical behaviour of NF membranes against monovalent ions. In general, the NF membrane showed lower rejection whereas RO membrane exhibited higher rejection value for the ions.

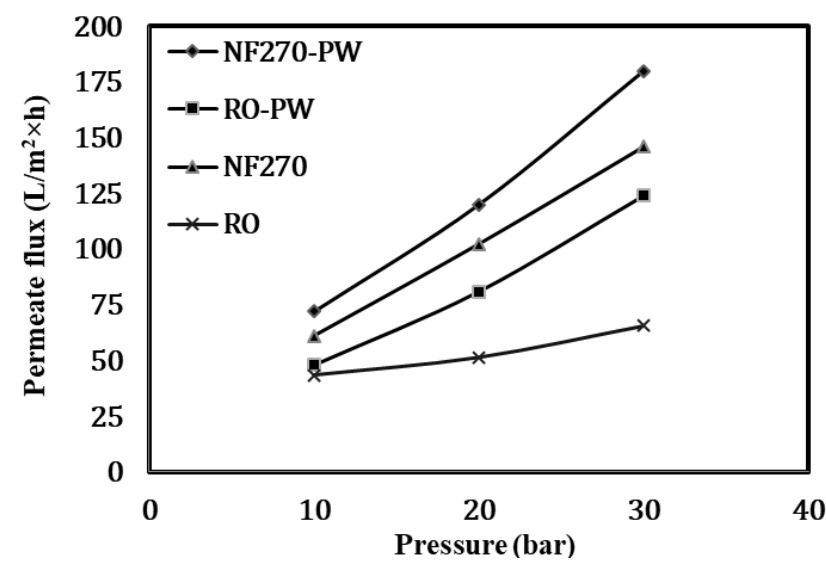

Figure 2: Pure water (PW) flux and permeate flux as function of feed pressure for the NF and RO membranes at $(22 \pm 2)^{\circ} \mathrm{C}$.

Table 3: Average rejection ratio for $N F$ and $R O$ membranes (standard deviation)

\begin{tabular}{llll}
\hline & 10 bar & 20 bar & 30 bar \\
\hline NF270 & $63.8 \%( \pm 0.3 \%)$ & $64.6 \%( \pm 0.3 \%)$ & $66.6 \%( \pm 0.3 \%)$ \\
RO & $97.6 \%( \pm 5 \%)$ & $97.9 \%( \pm 3 \%)$ & $98.4 \%( \pm 3.7 \%)$ \\
\hline
\end{tabular}

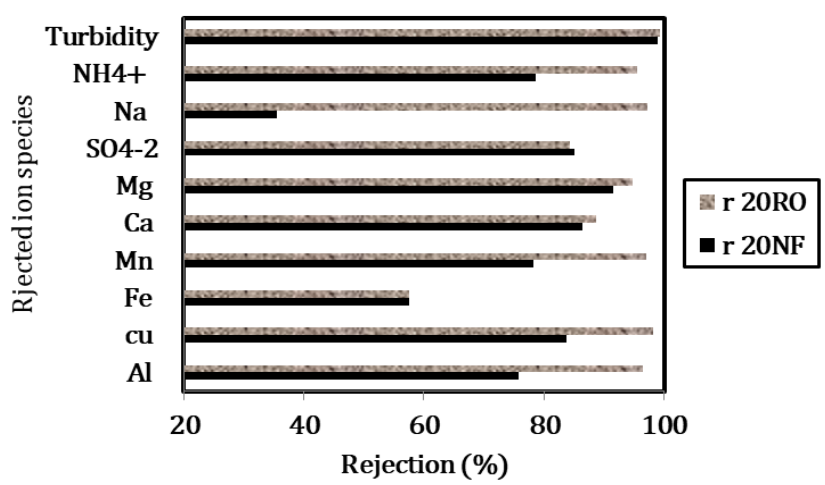

Figure 3: Selectivity of the NF and RO membranes at ambient temperature $(22 \pm 2)^{\circ} \mathrm{C}$ and TMP of 20 bar.

Table 4: Comparison permeates characteristics for the NF and RO membrane systems with TS266 and WHO water quality criteria at 20 bar (b proposed as health-based guideline).

\begin{tabular}{|c|c|c|c|c|c|c|c|c|}
\hline \multirow{2}{*}{ Parameter } & \multirow{2}{*}{ Unit } & \multirow{2}{*}{ Raw Wastewater } & \multicolumn{2}{|c|}{ Permeate Concentration } & \multicolumn{2}{|c|}{ Removal Efficiency } & \multicolumn{2}{|c|}{ Standards } \\
\hline & & & $\mathrm{NF}$ & RO & $\%, \mathrm{NF}$ & $\%, \mathrm{RO}$ & TS266 & $\mathrm{WHO}$ \\
\hline Al & $\mu \mathrm{g} / \mathrm{L}$ & 9.6 & 2.3 & 0.3 & 76.0 & 96.9 & 200 & 100 \\
\hline $\mathrm{NH}_{4}^{+}$ & $\mathrm{mg} / \mathrm{L}$ & 2.89 & 0.62 & 0.037 & 78.5 & 98.7 & 0.5 & 1.5 \\
\hline $\mathrm{Na}$ & $\mathrm{mg} / \mathrm{L}$ & 389 & 251 & 11 & 35.5 & 97.2 & 200 & 200 \\
\hline $\mathrm{SO}_{4}^{-2}$ & $\mathrm{mg} / \mathrm{L}$ & 12,6 & 1.89 & 0.92 & 85.5 & 92.9 & 250 & 500 \\
\hline $\mathrm{Mg}$ & $\mathrm{mg} / \mathrm{L}$ & 33.62 & 2.88 & 0.18 & 91.4 & 99.5 & n.p. ${ }^{b}$ & n.p. ${ }^{b}$ \\
\hline $\mathrm{Ca}$ & $\mathrm{mg} / \mathrm{L}$ & 31.10 & 4.24 & 2.88 & 86.4 & 90.7 & n.p. ${ }^{b}$ & 300 \\
\hline $\mathrm{Mn}$ & $\mu \mathrm{g} / \mathrm{L}$ & 3 & 0.5 & 0.05 & 83.3 & 98.3 & 50 & 100 \\
\hline $\mathrm{Fe}$ & $\mu \mathrm{g} / \mathrm{L}$ & 100 & 4.3 & 4.3 & 57.0 & 57.0 & 200 & 300 \\
\hline $\mathrm{Cu}$ & $\mathrm{mg} / \mathrm{L}$ & 0.07 & 0.011 & 0.001 & 84.3 & 98.6 & 2 & 2 \\
\hline Turbidity & NTU & 91 & 0.88 & 0.53 & 99.0 & 99.4 & 1 & 5 \\
\hline $\mathrm{pH}$ & & 8.9 & 8.5 & 8.0 & 7.5 & 10.1 & $6.5-9.5$ & $6.5-8.0$ \\
\hline Conductivity & $\mu \mathrm{s} / \mathrm{cm}$ & 1656 & 586 & 34 & 64.5 & 97.9 & 2500 & 2500 \\
\hline
\end{tabular}


The Use of NF ANd RO Membrane System for ReClamation ANd ReCYcling of WasteWATERS Generated from..., Y. Yildirim, et. al.

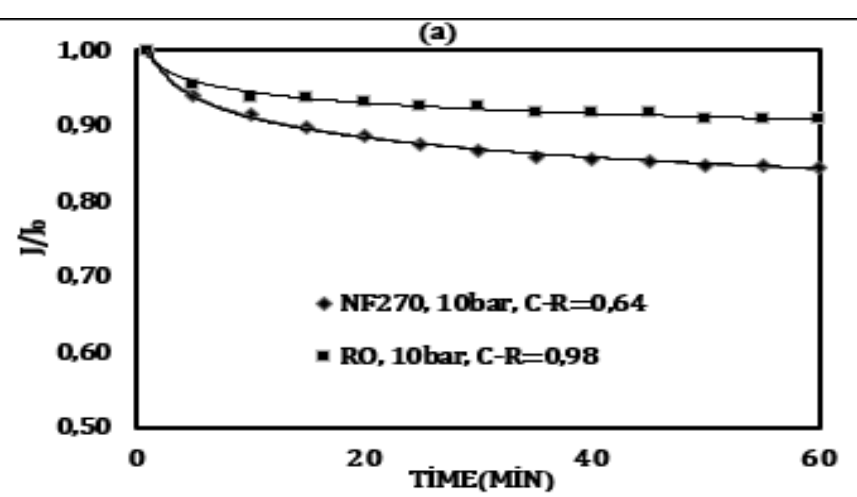

(b)

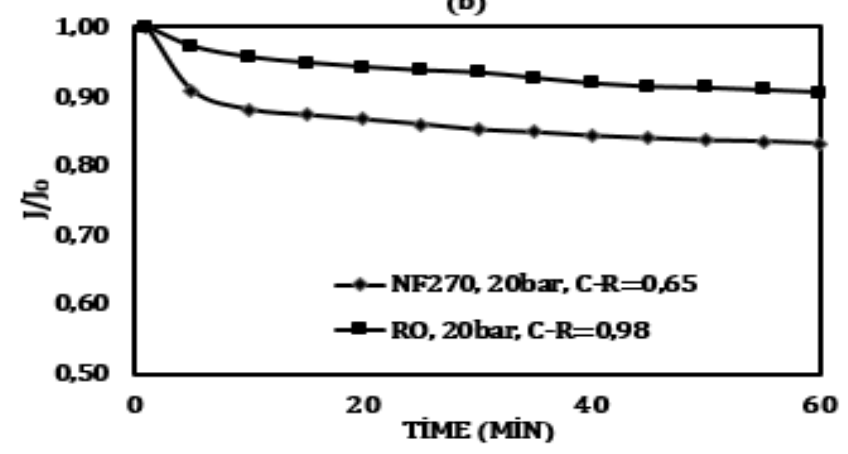

(c)

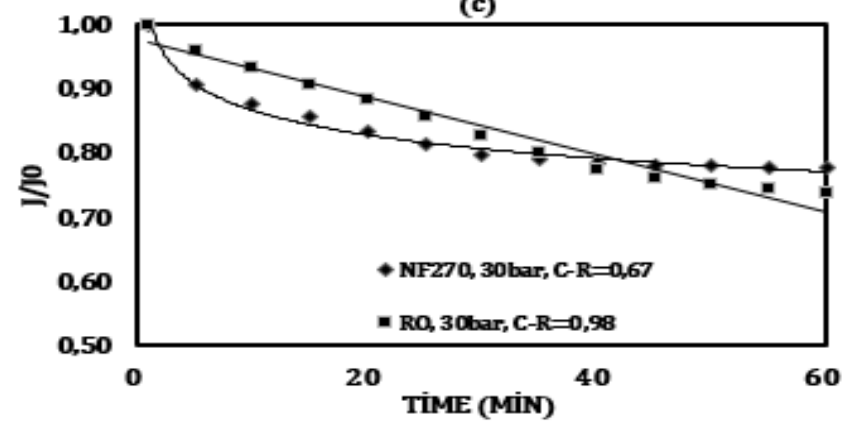

Figure 4: Relative flux decline compared to initial permeate flux for different experimental conditions at ambient temperature $(22 \pm 2)^{\circ} \mathrm{C}$. Codes: NF270nanofiltration, $R O$-reverse osmosis membrane, $C$ original mine water, $R$-rejection.

\subsection{Flux Variation as Function of Time}

Fig. 4(a, b, c) shows the flux variation for permeation test using the NF and RO membranes at three different experimental conditions as a function of time. During the wastewater filtration using RO membrane, it can be seen that the flux declined as function of time in the two phases. The first flux decline was exponential at the beginning and the second flux decline was linear after the exponential decrease. Exponential decline occurs because of the membrane compaction, and concentration polarization impacts at the starting of filtration experiments. Linear decline occurs after an equilibrium state of the membrane compaction and concentration polarization. The equilibrium state occurs either because of reaching a minimum constant flux level or because of scaling effects onto membrane. Exponential decrease and linear decrease were observed for each of the experimental studies except for operating 30 bar of RO membrane. Flux decrease for all operating of NF membrane is higher than flux decrease for all operating of RO membrane except for operating 30 bar of RO membrane. This condition may be explained that NF permeability is more than RO permeability. In the end of the operating under 30 bar of RO membrane, it is observed that the flux of RO membrane decreased linearly because of scaling onto the RO membrane surface. Additionally, small white particles were seen onto the RO membrane surface. These particles caused the scaling onto the RO membrane surface and so flux declined linearly.

\section{CONCLUSION}

Cross flow pressure driven membrane system was used to treat the coal mining wastewater. The raw wastewater permeate at 20 bar pressure of NF and RO membranes were analysed. Ammonium, sodium and turbidity of raw wastewater were above the limit values specified by TSS 266 and WHO standards but $\mathrm{Al}, \mathrm{SO}_{4}{ }^{-2}, \mathrm{Mg}, \mathrm{Ca}, \mathrm{Mn}, \mathrm{Fe}, \mathrm{Cu}$, and conductivity parameters were below the limit. However, coal mining wastewater treated using the RO membrane at 20 bar feed pressure showed the best treatment performance, providing the water product having a clean drinking water quality specification which satisfied both TS 266 and WHO standards. Also, the RO membrane has higher selectivity than NF membrane but have lower permeate flux than the NF membrane. In a nutshell, using the NF and RO membrane system, the wastewaters generated from a hard coal mining may be treated to produce a highquality effluent along with low energy consumption and reduced usage of chemicals in respect to the traditional wastewater treatment systems.

\section{ACKNOWLEDGEMENT}

The funding provided by Bulent Ecevit University (Project no. 2014 - $77047330-01$ ) is acknowledged.

\section{REFERENCES}

[1] Bunani, S., Yörükoğlu, E., Sert, G., Yüksel, Ü., Yüksel, M., Kabay, N. "Application of nanofiltration for reuse of municipal wastewater 
and quality analysis of product water". Desalination, Vol. 315 pp 33-36, 2013.

[2] Aloui, F., Khoufi, S., Loukil, S., Sayadi, S. "Performances of an activated sludge process for the treatment of fish processing saline wastewater". Desalination, Vol. 246 pp 389396, 2009.

[3] Marcucci, M., Nosenzo, G., Capannelli, G., Ciabatti, I., Corrieri, D., Ciardelli, G. "Treatment and reuse of textile effluents based on new ultrafiltration and other membrane technologies". Desalination, Vol. 138 pp 75-82, 2001.

[4] Perry, M., Linder, C. "Intermediate reverse osmosis ultrafiltration (RO UF) membranes for concentration and desalting of low molecular weight organic solutes". Desalination, Vol. 71 pp 233-245, 1989.

[5] Rautenbach, R., Mellis, R. "Hybrid processes involving membranes for the treatment of highly organic/inorganic contaminated waste water". Desalination, Vol. 101 pp 105-113, 1995.

[6] Bowen, W. R. Mukhtar, H. "Characterisation and prediction of separation performance of nanofiltration membranes". Journal of Membrane Science, Vol. 112 pp 263-274, 1996.

[7] Ricci, B. C., Ferreira C. D., Aguiar, A. O., Amaral, M. C. S. "Integration of nanofiltration and reverse osmosis for metal separation and sulfuric acid recovery from gold mining effluent". Separation and Purification Technology, Vol. 154 pp 11-21, 2015.

[8] Fu, F., Wang, Q. "Removal of heavy metal ions from wastewaters: a review" Journal of Environmental Management, Vol. 92 pp 407418, 2011.

[9] Qi, L., Wang, X., Xu, Q. "Coupling of biological methods with membrane filtration using ozone as pre-treatment for water reuse". Desalination, Vol. 270 pp 264-268, 2011.

[10] Lee, J. W., Kwon, T. O., Moon, S. "Performance of polyamide reverse osmosis membranes for steel wastewater reuse". Desalination, Vol. 189 pp 309-322, 2006.

[11] Hafez, A., Khedr, M., Gadallah, H. "Wastewater treatment and water reuse of food processing industries. Part II: Techno-economic study of a membrane separation technique". Desalination, Vol. 214 pp 261-272, 2007.

[12]. Alkhatim, H. S., Alcaina, M. I., Soriano, E., Iborra, M. I., Lora, J., Arnal, J. "Treatment of whey effluents from dairy industries by nanofiltration membrane". Desalination, Vol. pp 119 177-183, (1998).

[13] Vourch, M., Balannec, B., Chaufer, B., Dorange, G. "Treatment of dairy industry wastewater by reverse osmosis for water reuse", Desalination, Vol. 219 pp 190-202, 2008.

[14] Qin, J., Oo H. M., Kekre A. K. "Nanofiltration for recovering wastewater from a specific dyeing facility". Sep. Purif. Technol., Vol. 56 pp 199203, 2007.

[15] Capar, G., Yetis, U., Yilmaz, L. "Reclamation of printing effluents of a carpet manufacturing industry by membrane processes". J. Membr. Sci., Vol. 277 pp 120-128, 2006.

[16] Dasgupta, J., Sikder, J., Chakraborty, S., Curcio, S., Drioli, E. "Remediation of textile effluents by membrane-based treatment techniques: A state of the art review", Journal of Environmental Management, Vol. 147 pp 55-72, 2015.

[17] Balcik-Canbolat, C., Sengezer, C., Sakar, H., Karagunduz, A., Keskinler, B. "Recovery of real dye bath wastewater using integrated membrane process: considering water recovery, membrane fouling and reuse potential of membranes". Instrumentation Science and Technology, Vol. 38 pp 2668-2676, 2017.

[18] Yu, S. C., Chen, Z. W., Liu, M. H., Zhao, J. W. "Comparative Study on the Treatment of Biologically Treated Textile Effluent by Nanofiltration and Reverse Osmosis for Water Reuse". Advanced Materials Research, Vol. 441 pp 584-588, 2012.

[19] Dolar, D. Košutić, K. Vučić, B. "RO/NF treatment of wastewater from fertilizer factory removal of fluoride and phosphate". Desalination, Vol. 265 pp 237-241, 2011.

[20] Corbett, R.G. "Effects of coal mining on ground and surface water quality, Monongalia County West Virginia". Science Total Environment, Vol. 8 pp 21-38, 1977.

[21] Galloux J., Chekli, L., Phuntsho, S., Tijing, L. D., Jeong, S., Zhao, Y. X., Gao B. Y., Park, S. H., Shon, H. K. "Coagulation performance and floc characteristics of polytitanium tetrachloride and titanium tetrachloride compared with ferric chloride for coal mining wastewater treatment". Separation and Purification Technology, Vol. 152 pp 94-100, 2015.

[22] Sivakumar M., Ramezanianpour M., Halloran G. O. "Mine Water Treatment Using a Vacuum Membrane Distillation System". APCBEE Procedia, Vol. 5 pp 157-162, 2013. 
[23] Tripathy, T., Karmakar, N., Singh R. "Development of novel polymeric flocculant based on grafted sodium alginate for the treatment of coal mine wastewater". J. Appl. Polym. Sci., Vol. 82 pp 375-382, 2001.

[24] Kusin, F., Jarvis, A., Gandy, C. "Hydraulic performance assessment of passive coal mine water treatment systems in the UK". Ecological Engineering, Vol. 49 pp 233-243, 2012.

[25] Sapsford, D., Watson, I. "A process-orientated design and performance assessment methodology for passive mine water treatment systems". Ecol. Eng., Vol. 37 pp 970-975, 2011.

[26] Feng, D., Aldrich, C., Tan, H. "Treatment of acidic mine water by use of heavy metal precipitation and ion exchange". Minerals Engineering, Vol. 13 pp 623-642, 2000.

[27] Alkhudhri, A., Darwish, N., Hilal, N. "Membrane distillation: A comprehensive review". Desalination, Vol. 287 pp 2-18, 2012.

[28] Yildirim, Y., Topaloğlu A. "The use of ultrafiltration membrane systems to treat waste waters generated from hard coal mining. Journal of Young Scientist" Vol. 3 pp 63-66, 2014.

[29] TS 266, "Water intended for human consumption", Turkish Standards Institution. (2005).

[30] WHO (World Health Organization), Guidelines for Drinking Water Quality, (3rd ed.), World Health Organization, Geneva (2008). 